\title{
Article \\ In Silico and Ex Vivo Studies on the Spasmolytic Activities of Fenchone Using Isolated Guinea Pig Trachea
}

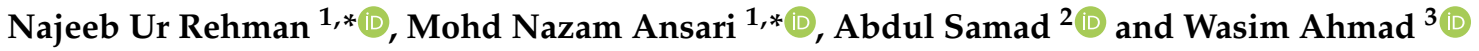 \\ 1 Department of Pharmacology \& Toxicology, College of Pharmacy, Prince Sattam Bin Abdulaziz University, \\ Al-Kharj 11942, Saudi Arabia \\ 2 Department of Pharmaceutical Chemistry, Faculty of Pharmacy, Tishk International University, \\ Erbil 44001, Iraq; abdul.samad@tiu.edu.iq \\ 3 Department of Pharmacy, Mohammed Al-Mana College for Medical Sciences, Dammam 34222, Saudi Arabia; \\ wasimahmadansari@yahoo.com \\ * Correspondence: n_rehman5@hotmail.com (N.U.R.); nazam.ansari@gmail.com (M.N.A.); \\ Tel.: +966-11-5886-035 (N.U.R.); +966-11-5886-037 (M.N.A.)
}

check for updates

Citation: Rehman, N.U.; Ansari, M.N.; Samad, A.; Ahmad, W. In Silico and Ex Vivo Studies on the Spasmolytic Activities of Fenchone Using Isolated Guinea Pig Trachea. Molecules 2022, 27, 1360. https:/ / doi.org/10.3390/molecules27041360

Academic Editor: Guy P.P. Kamatou

Received: 7 January 2022

Accepted: 14 February 2022

Published: 17 February 2022

Publisher's Note: MDPI stays neutral with regard to jurisdictional claims in published maps and institutional affiliations.

Copyright: (c) 2022 by the authors. Licensee MDPI, Basel, Switzerland. This article is an open access article distributed under the terms and conditions of the Creative Commons Attribution (CC BY) license (https:// creativecommons.org/licenses/by/ $4.0 /)$.

\begin{abstract}
Fenchone is a bicyclic monoterpene found in a variety of aromatic plants, including Foeniculum vulgare and Peumus boldus, and is used in the management of airways disorders. This study aimed to explore the bronchodilator effect of fenchone using guinea pig tracheal muscles as an ex vivo model and in silico studies. A concentration-mediated tracheal relaxant effect of fenchone was evaluated using isolated guinea pig trachea mounted in an organ bath provided with physiological conditions. Sustained contractions were achieved using low $\mathrm{K}^{+}(25 \mathrm{mM})$, high $\mathrm{K}^{+}(80 \mathrm{mM})$, and carbamylcholine (CCh; $1 \mu \mathrm{M})$, and fenchone inhibitory concentration-response curves (CRCs) were obtained against these contractions. Fenchone selectively inhibited with higher potency contractions evoked by low $\mathrm{K}^{+}$compared to high $\mathrm{K}^{+}$with resultant $\mathrm{EC}_{50}$ values of $0.62 \mathrm{mg} / \mathrm{mL}(0.58-0.72 ; n=5)$ and $6.44 \mathrm{mg} / \mathrm{mL}(5.86-7.32 ; n=5)$, respectively. Verapamil (VRP) inhibited both low and high $\mathrm{K}^{+}$contractions at similar concentrations. Pre-incubation of the tracheal tissues with $\mathrm{K}^{+}$channel blockers such as glibenclamide (Gb), 4-aminopyridine (4-AP), and tetraethylammonium (TEA) significantly shifted the inhibitory CRCs of fenchone to the right towards higher doses. Fenchone also inhibited CCh-mediated contractions at comparable potency to its effect against high $\mathrm{K}^{+}[6.28 \mathrm{mg} / \mathrm{mL}$ $(5.88-6.42, n=4) ; \mathrm{CCh}]$ and [6.44 mg/mL (5.86-7.32; $n=5)$; high $\left.\mathrm{K}^{+}\right]$. A similar pattern was obtained with papaverine (PPV), a phosphodiesterase (PDE), and $\mathrm{Ca}^{2+}$ inhibitor which inhibited both CCh and high $\mathrm{K}^{+}$at similar concentrations [10.46 $\mu \mathrm{M}(9.82-11.22, n=4)$; CCh] and [10.28 $\mu \mathrm{M}(9.18-11.36 ; n=5)$; high $\mathrm{K}^{+}$]. However, verapamil, a standard $\mathrm{Ca}^{2+}$ channel blocker, showed selectively higher potency against high $\mathrm{K}^{+}$compared to $\mathrm{CCh}$-mediated contractions with respective $\mathrm{EC}_{50}$ values of $0.84 \mathrm{mg} / \mathrm{mL}$ $(0.82-0.96 ; n=5) 14.46 \mathrm{mg} / \mathrm{mL}(12.24-16.38, n=4)$. The PDE-inhibitory action of fenchone was further confirmed when its pre-incubation at 3 and $5 \mathrm{mg} / \mathrm{mL}$ potentiated and shifted the isoprenaline inhibitory CRCs towards the left, similar to papaverine, whereas the $\mathrm{Ca}^{2+}$ inhibitory-like action of fenchone pretreated tracheal tissues were authenticated by the rightward shift of $\mathrm{Ca}^{2+} \mathrm{CRCs}$ with suppression of maximum response, similar to verapamil, a standard $\mathrm{Ca}^{2+}$ channel blocker. Fenchone showed a spasmolytic effect in isolated trachea mediated predominantly by $\mathrm{K}^{+}$channel activation followed by dual inhibition of PDE and $\mathrm{Ca}^{2+}$ channels. Further in silico molecular docking studies provided the insight for binding of fenchone with $\mathrm{Ca}^{2+}$ channel $(-5.3 \mathrm{kcal} / \mathrm{mol})$ and $\mathrm{K}^{+}$channel $(-5.7)$, which also endorsed the idea of dual inhibition.
\end{abstract}

Keywords: fenchone; $\mathrm{K}^{+}$channel opener; carbamylcholine; papaverine; PDE inhibitor; $\mathrm{Ca}++$ channel blocker

\section{Introduction}

Bronchodilators are used to treat respiratory disorders such as asthma and chronic obstructive pulmonary disease (COPD), both acutely and on a long-term basis. [1,2]. COPD 
is a common major disabling syndrome responsible for considerable morbidity and mortality worldwide [3]. It is one of the important airways ailments, characterized by periodic wheezing following cough and chest rigidity mainly because of the obstruction in outflowing air [4]. Current drugs used as the bronchodilator for the management of COPD, such as anticholinergic agents that were introduced to Western medicine in the early 1800s [5], have major limitations such as dry mouth, blurred vision, nausea, decreased gut mobility, urinary retention, and tachycardia. Due to these side effects, anticholinergics were displaced by adrenergic agonists in the 1920s [6].

Natural remedies and medicinal plants are crucial in the search for new treatment options. The bulk of medicines in use today are made up of plant extracts, semi-synthetic derivatives, and synthetic chemicals inspired by natural ingredients [7]. As a result, natural ingredients are excellent starting points for the development of new medications for a wide range of conditions, along with respiratory problems [8]. Several plant species and isolated chemicals, including terpenes, showed promise in the treatment of respiratory inflammation, atopic dermatitis, arthritis, and neuro-inflammation in recent years [9]. Furthermore, several terpenes derived from traditional Chinese medicines for the treatment of asthma, such as borneol and terpineol, reduced histamine-induced in vitro bronchoconstriction of isolated tracheal smooth muscles, showing anti-asthmatic activity [10]. The monoterpene fenchone (1,3,3- rimethylbicyclo[2.2.1] heptane-2-one) was chosen for this study based on this criterion. Fenchone is a bicyclic monoterpene found in the essential oils of plants, including Foeniculum vulgare and Peumus boldus that is used to treat respiratory and gastrointestinal problems. Previous reports show that fenchone possesses antifungal, antisecretory, antimotility, and antidiarrheal activities [11]. Its antimicrobial potential was reported by Kupeli et al. [12], whereas Algieri et al. [13] reported the antioxidant activity of fenchone. Based on the reported result of the spasmolytic potential of monoterpene in different smooth muscles, fenchone was selected for this study to test its possible bronchodilator effect using isolated tracheal smooth muscles of guinea pigs and to probe the detailed pharmacodynamics using ex vivo and in silico molecular docking models.

\section{Materials and Methods}

\subsection{Chemicals and Reagents}

Fenchone [(+)-fenchone] was obtained from Alfa Aesar with 98\% purity and CAS: 4695-62-9. Carbamylcholine, verapamil, glibenclamide, tetraethylammonium (TEA), and 4aminopyridine were purchased from Sigma-Aldrich. All chemicals used were of analytical grade, and fresh dilutions were prepared on the day of the experiment.

\subsection{Ethics Statement}

Experiments were carried out in accordance with the National Research Council's Institute of Laboratory Animal Resources, Commission on Life Sciences rules [14]. The study was approved by the Bio-Ethical Research Committee (BERC) at Prince Sattam Bin Abdulaziz University under the reference number BERC-001-12-19.

\subsection{Animals}

Guinea pigs (500-550 g) of both sexes and local breeds were obtained from King Saud University's lab animal unit. Animals were housed in the Animal Care Unit, College of Pharmacy, PSAU, KSA, where they were kept at a constant temperature of $23-25^{\circ} \mathrm{C}$ and fed a commercial standard meal and had free access to tap water.

\subsection{Tissue Preparation}

The guinea pigs were killed by cervical dislocation followed by tracheal tube isolation. The tracheal tubes were immersed in Krebs solution, which was kept at $37^{\circ} \mathrm{C}$ and gassed with the carbogen (95 percent $\mathrm{O}_{2}: 5 \% \mathrm{CO}_{2}$ ) [15].

The trachea was cut into 2- to $3 \mathrm{~mm}$ wide rings after adherent fat, and connective tissues were carefully removed. To make a tracheal chain, all of the rings were sliced 
open, opposing the trachealis muscle, and sutured together [16]. The strips of trachea were then mounted in an organ bath filled with enough Krebs solution to dip the tissue, and an optimal temperature $\left(37^{\circ} \mathrm{C}\right)$ was maintained by the attached thermocirculator with carbogen gas aeration. A constant tension $(1 \mathrm{~g})$ was given to each tracheal strip throughout the experiment. After an equilibration period of at least $60 \mathrm{~min}$, the preparations were tested for contractile responses to carbamylcholine $(\mathrm{CCh}, 1 \mu \mathrm{M})$ repeatedly using the isometric force transducer, connected to emkaBATH data acquisition system (France). Once the tonic contraction became stable, the test material $\mathrm{EC}_{50}$ values were obtained by constructing the inhibitory concentration-response curves (CRCs) by the cumulative addition of test substance in the organ bath in a concentration-dependent manner starting from a lower concentration of $0.01 \mathrm{mg} / \mathrm{mL}$ to the maximum tested final bath concentration of $10 \mathrm{mg} / \mathrm{mL}$. To assess the pharmacodynamics involved in their bronchial relaxant activity, different spasmogen-mediated contractions were used [17].

\subsection{Determination of the Possible Mechanisms of Action}

The spasmolytic effects of the test samples were tested on low $\mathrm{K}^{+}(25 \mathrm{mM})$ and high $\mathrm{K}^{+}(80 \mathrm{mM})$-induced contractions, respectively, to elucidate the possible involvement of $\mathrm{K}^{+}$ channel opening and/or $\mathrm{Ca}^{2+}$ channel inhibitory-like mechanism(s) [18]. Fenchone was added in a cumulative method after a sustained contraction in response to low and high $\mathrm{K}^{+}$to produce concentration-dependent inhibitory responses. The relaxation of the tissue preparation was calculated as a percentage of the $\mathrm{K}^{+}$-mediated control contraction.

To characterize the specific type of $\mathrm{K}^{+}$channel activation involved in the bronchodilator effect, the bronchodilator effects of fenchone were reproduced in the absence and presence of different $\mathrm{K}^{+}$channel antagonists such as TEA $(1 \mathrm{mM})$; a nonselective $\mathrm{K}^{+}$channel blocker [19], 4-aminopyridine (4-AP, $100 \mu \mathrm{M})$; a selective blocker of voltage-sensitive $\mathrm{K}^{+}$channels [20] and glibenclamide $(\mathrm{Gb}, 10 \mu \mathrm{M})$; a selective blocker of ATP-dependent $\mathrm{K}^{+}$ channels [21]. The selection of the concentrations of these antagonists was facilitated based on the previously reported studies conducted in different types of isolated tissues [19-21]. The effect of test material on the blockade of $\mathrm{Ca}^{2+}$ channels is based on the pilot studies conducted against high $\mathrm{K}^{+}$-mediated contractions [22]. $\mathrm{K}^{+}$at a concentration more than $30 \mathrm{mM}$ produces excitatory peaks in the isolated smooth tissues via the opening up of voltage-driven $\mathrm{Ca}^{2+}$ channels, particularly L-type $\mathrm{Ca}^{2+}$ channels, thus facilitating the inward movements of calcium ions from the extracellular fluid. This will eventually elevate the intracellular concentration of $\mathrm{Ca}^{2+}$ that finally produces strong contractions in the preparations $[23,24]$. Any agent that will suppress high $\mathrm{K}^{+}$-mediated excitations might be labeled as a $\mathrm{Ca}^{2+}$ channel inhibitor [25], while $\mathrm{K}^{+}$channel openers will selectively inhibit low $\mathrm{K}^{+}$-evoked spasms, whereas $\mathrm{Ca}^{2+}$ channel inhibitors show comparable potencies to relax low and high $\mathrm{K}^{+}$-evoked spasms [26]. Hence, these experiments differentiate $\mathrm{K}^{+}$ channel openers from $\mathrm{Ca}^{2+}$ channel blockers [27]. Once the contraction is sustained in the form of a straight line after the application of $\mathrm{K}^{+}$, the test compound and/or standard drug was added to the organ bath in an accumulative manner to finally obtain inhibitory CRCs [17]. The tracheal tissues were stabilized in standard Krebs solution, which was then replaced with a calcium-free Krebs solution containing a chelating agent, EDTA, for roughly half an hour, resulting in calcium-free tracheal segments. This $\mathrm{Ca}^{2+}$-free Krebs solution was then replaced with Krebs solution, $\mathrm{K}^{+}$-rich and $\mathrm{Ca}^{2+}$-free [28]. After an incubation period for a period of around half an hour in a calcium-free and potassium-rich bathing solution, the control curves of calcium were obtained in a dose-related manner. When the control CRCs were attained, the segments were pre-incubated with increasing concentrations of the test samples for an hour, and the calcium curves were re-obtained to observe the CCB-like actions [22]. To elucidate an additional mechanism(s), the test material inhibitory effect against $\mathrm{CCh}$ and high $\mathrm{K}^{+}$was critically observed, and the involvement of a PDE-inhibitory-like mechanism is expected if the CCh and high $\mathrm{K}^{+}$are inhibited at comparable potencies. The PDE-inhibitory-like mechanism was confirmed further by isoprenaline-mediated inhibition in CCh-induced contraction in the absence (control) and 
presence (test) of test samples pre-incubation, as PDE-inhibitors are known to potentiate isoprenaline effects $[29,30]$.

\subsection{Molecular Docking Studies}

To obtain insight into possible molecular mechanisms for spasmolytic activities of fenchone, molecular docking studies were carried out on the various phosphodiesterase receptor proteins and calcium ion channels. The protein receptors considered for these docking studies had PDB IDs 3ITU, 4NPW, 5LAQ, 6JPA, 6EBM, and 7VNP. The studies were carried out on a Windows 10 platform using the AutoDock Vina program on the PyRx platform [31]. Discovery Studio 4, provided by BIOVIA solutions, was used for the visualization of docked poses of ligands and proteins [32]. The crystal structures of the proteins were downloaded from the protein databank found on the RCSB website. The downloaded proteins were subjected to preparing and repairing processes for the missing residues and charges using a Discovery Studio visualizer. The co-crystallized ligands were removed from their proteins and saved separately in PDB format, which was used for redocking in the active domains of their respective proteins to validate our docking methodology [33]. The structures of fenchone and papaverine were downloaded from the protein database and then converted to PDB format with the help of Open Babel software.

\subsection{ADMET Studies}

ADMET studies (Adsorption, Distribution, Metabolism, Excretion, and Toxicity) are the key characteristics to be considered while developing a novel molecule in the drug discovery cascade. ADMET studies of fenchone were predicted by pkCSM software, which is a web-based program [34]. First of all, SMILES for the fenchone molecule were taken from the PubChem database, and the same software was used to carry out complete ADMET profiling of fenchone.

\subsection{Statistical Analysis}

Results are presented as mean \pm standard error of the mean $(n=$ number of experiments) and median effective concentrations $\left(\mathrm{EC}_{50}\right)$ with $95 \%$ confidence intervals (CI). The bronchodilator activities were evaluated using one-way ANOVA and Dunnett's test. Statistical significance is defined as $p<0.05$. Non-linear regression was used to evaluate the concentration-response curves using the standard statistical software (GraphPad, version-4, San Diego, CA, USA).

\section{Results}

\subsection{Preliminary Screening of Fenchone for Spasmolytic Effect}

Fenchone inhibited both $\mathrm{K}^{+} 25$ and $\mathrm{K}^{+} 80$, evoking sustained spasms with higher observed potency than is required to inhibit $\mathrm{K}^{+} 25$-mediated spasms compared to high $\mathrm{K}^{+}$ $(p<0.05)$ with obtained $\mathrm{EC}_{50}$ values of $0.62 \mathrm{mg} / \mathrm{mL}(0.58-0.72 ; n=6)$ and $6.44 \mathrm{mg} / \mathrm{mL}$ $(5.86-7.32 ; n=5-6)$, respectively (Figure 1A). Verapamil, used as a standard control drug, inhibited both $\mathrm{K}^{+} 25$ and $\mathrm{K}^{+} 80$, evoking spasms in tracheal strips at similar concentrations $(p>0.05)$ with recorded $\mathrm{EC}_{50}$ values of $0.92 \mathrm{mg} / \mathrm{mL}(0.86-0.98 ; n=5)$ and $0.84 \mathrm{mg} / \mathrm{mL}$ $(0.82-0.96 ; n=6)$, as shown in Figure 1B.

\subsection{Determination of the Possible Effect of Fenchone on Activation of Subtype of $\mathrm{K}^{+}$Channels}

After preliminary experiments, results observed higher potency against low $\mathrm{K}^{+}$and fenchone was tested for its spasmolytic effect in the presence of different $\mathrm{K}^{+}$channel antagonists (Figure 2). In the presence of $\mathrm{Gb}(10 \mu \mathrm{M})$, the spasmolytic effect of fenchone in isolated trachea against low $\mathrm{K}^{+}$-mediated contractions was shifted towards higher concentrations with $\mathrm{EC}_{50}$ values of $6.24 \mathrm{mg} / \mathrm{mL}(5.98-6.86 ; n=5)$ (Figure 2A). In parallel assays, 4-AP (1 mM) (Figure 2B) and TEA (10 mM) (Figure 2C) pre-incubated tracheal tissues also shifted the fenchone spasmolytic curves against low $\mathrm{K}^{+}$towards higher concentrations 
with obtained $\mathrm{EC}_{50}$ values of $5.78 \mathrm{mg} / \mathrm{mL}(5.44-5.92, n=5)$ and $6.22 \mathrm{mg} / \mathrm{mL}(5.84-6.72$, $n=5)$, respectively.

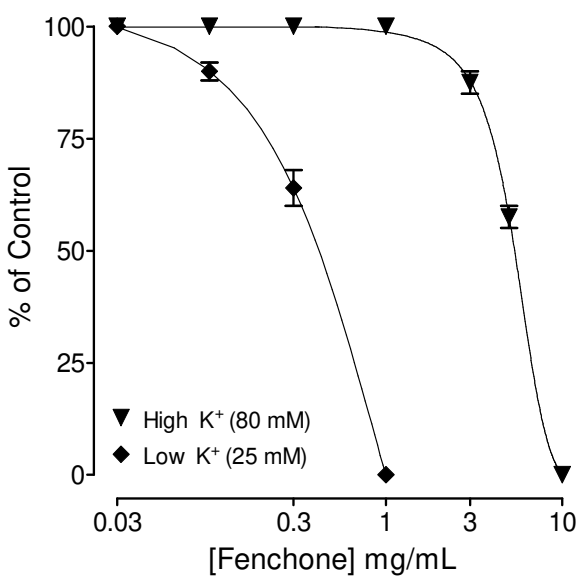

(A)

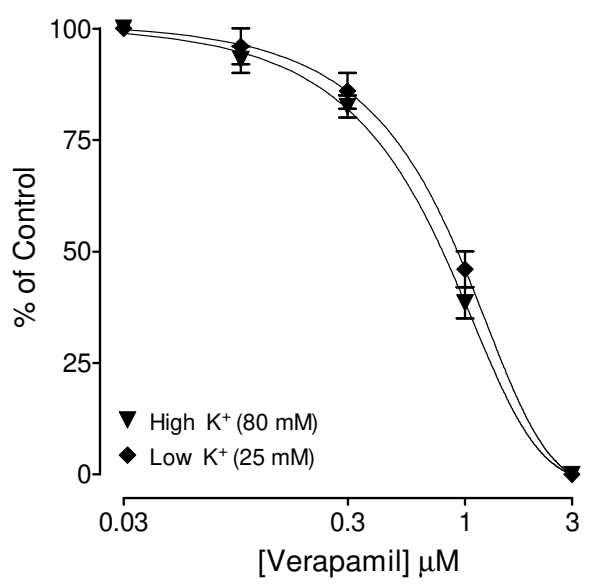

(B)

Figure 1. Concentration-dependent inhibitory effects of (A) fenchone and (B) verapamil against low $\mathrm{K}^{+}(25 \mathrm{mM})$ and high $\mathrm{K}^{+}(80 \mathrm{mM})$-induced contractions in isolated guinea pig tracheal tissues. Symbols represent mean \pm SEM; $n=4-5$.

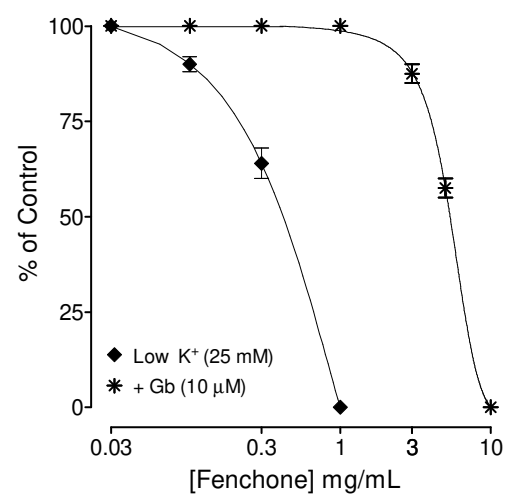

(A)

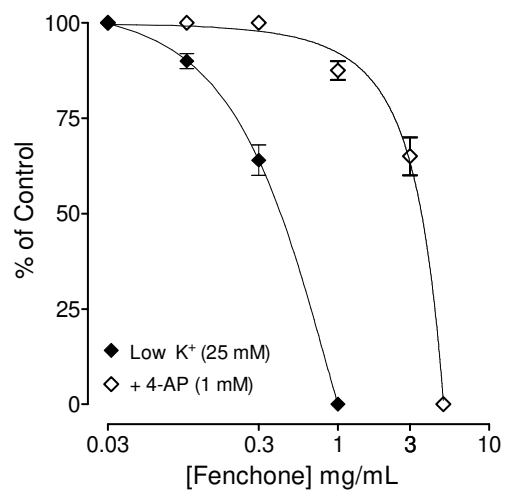

(B)

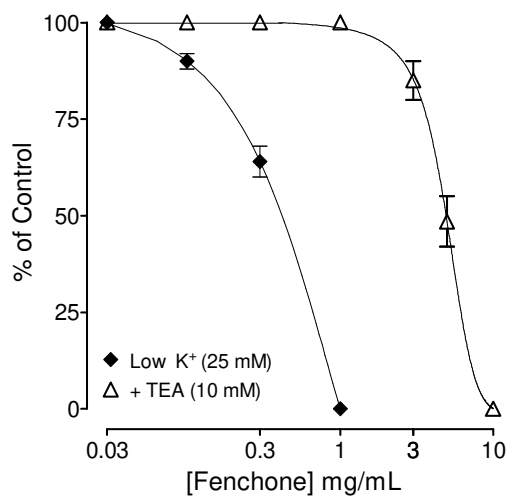

(C)

Figure 2. Effect of (A) glibenclamide (Gb; $10 \mu \mathrm{M})$, (B) 4-aminopyridine (4-AP; $1 \mathrm{mM}$ ) and (C) tetraethylammonium (TEA; $1 \mathrm{mM})$ on the inhibitory effects of Fenchone against low $\mathrm{K}^{+}(25 \mathrm{mM})$-induced contractions in isolated guinea pig tracheal tissues. Symbols represent mean \pm SEM; $n=4-5$.

\subsection{Confirmation of PDE Inhibitory-like Spasmolytic Effects of Fenchone}

The spasmolytic $\mathrm{CRC}$ s of fenchone against $\mathrm{CCh}$ and high $\mathrm{K}^{+}$at comparable $\mathrm{EC}_{50}$ values of $[6.28 \mathrm{mg} / \mathrm{mL}(5.88-6.42, n=4) ; \mathrm{CCh}]$ and $[6.44 \mathrm{mg} / \mathrm{mL}(5.86-7.32 ; n=5) ;$ high $\mathrm{K}^{+}$] (Figure 3A) was found similar to the inhibitory effect of standard drug, papaverine (Figure 3B), whereas verapamil showed selectively higher potency against high $\mathrm{K}^{+}$compared to CCh-mediated contractions with respective $\mathrm{EC}_{50}$ values of $0.84 \mathrm{mg} / \mathrm{mL}(0.82-0.96$; $n=5) 14.46 \mathrm{mg} / \mathrm{mL}(12.24-16.38, n=4)$, as shown in Figure 3C. Confirmation of the PDE-inhibitory effect was observed when tracheal tissues pre-incubated with fenchone (3 and $5 \mathrm{mg} / \mathrm{mL}$ ) potentiated and shifted isoprenaline-induced inhibitory curves to the left (Figure $4 \mathrm{~A}$ ) similar to papaverine ( 1 and $3 \mu \mathrm{M})$ (Figure $4 \mathrm{~B})$. In contrast, verapamil did not show any shift in the curves at both tested doses of 0.1 and $0.3 \mathrm{mg} / \mathrm{mL}$ (Figure 4C). 


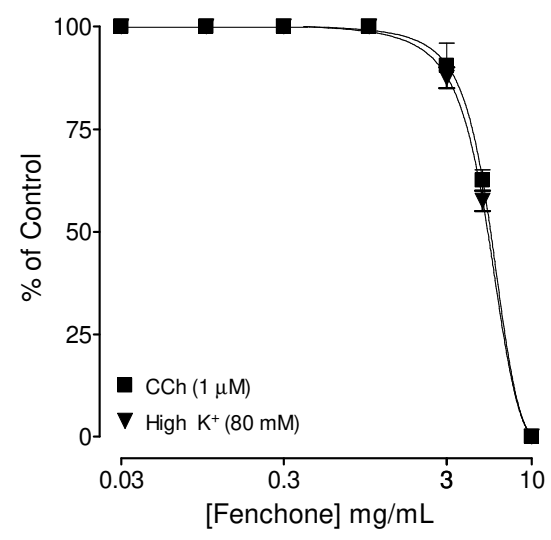

(A)

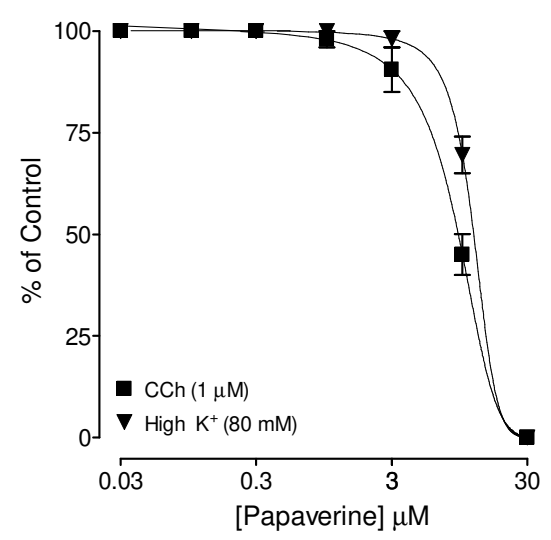

(B)

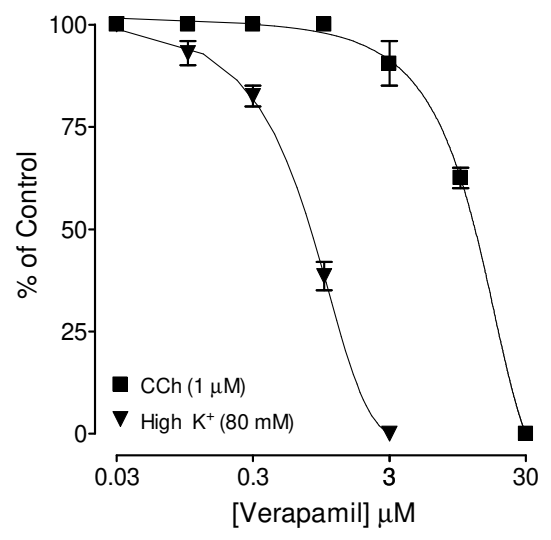

(C)

Figure 3. Concentration-dependent inhibitory effects of $(\mathbf{A})$ fenchone and $(\mathbf{B})$ papaverine and (C) verapamil against carbachol $(\mathrm{CCh} ; 1 \mu \mathrm{M})$ and high $\mathrm{K}^{+}(80 \mathrm{mM})$-induced contractions in isolated guinea pig tracheal tissues. Symbols represent mean \pm SEM; $n=4-5$.

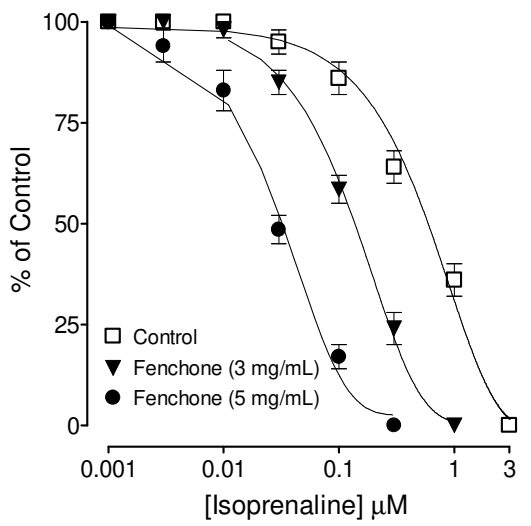

(A)

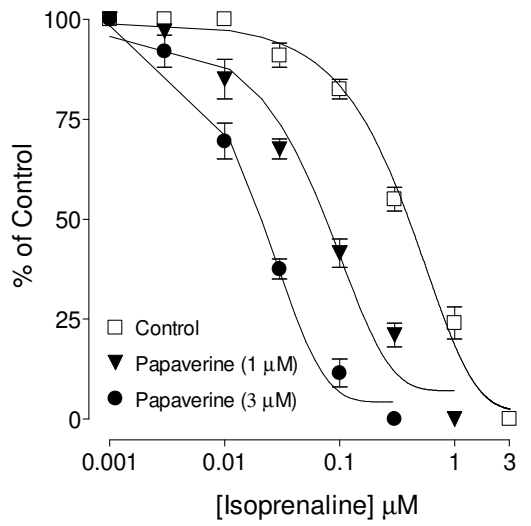

(B)

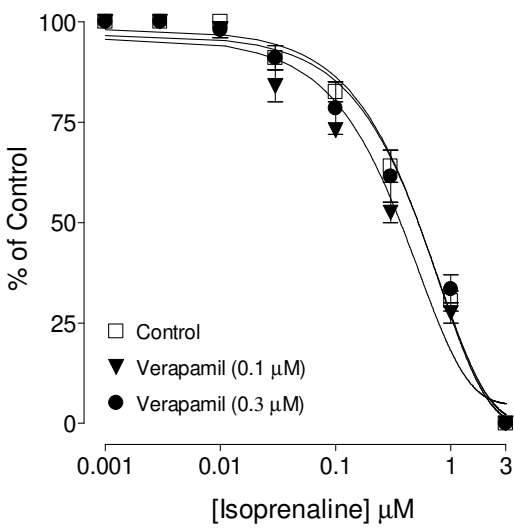

(C)

Figure 4. Inhibitory concentration-response curves of isoprenaline against carbachol (CCh; $1 \mu \mathrm{M})$ induced contractions in the absence and presence of the increasing concentrations of (A) fenchone, (B) papaverine, and (C) verapamil in guinea pig tracheal preparations. Symbols represent mean \pm SEM; $n=4-5$.

\subsection{Confirmation of Ca++ Channel Inhibitory-like Spasmolytic Effects of Fenchone}

In tracheal tissues, fenchone, the tested compound (Figure 5A), in a concentrationdependent manner ( 3 and $5 \mathrm{mg} / \mathrm{mL}$ ) similar to verapamil $(0.1$ and $0.3 \mu \mathrm{M})$ (Figure $5 \mathrm{~B}$ ), shifted the $\mathrm{Ca}^{2+} \mathrm{CRCs}$ to the right with suppression of the maximum response. Papaverine, a dual inhibitor of $\mathrm{Ca}^{2+}$ channels and PDE, also suppressed the maximum response of $\mathrm{Ca}^{2+}$ CRCs in a concentration-dependent manner ( 3 and $10 \mu \mathrm{M})$, as shown in Figure 5C.

\subsection{Molecular Docking Analyses}

Further, to obtain insight into the molecular mechanism of fenchone and its spasmolytic effects, molecular docking studies were carried out. Various receptors of PDE and calcium channel were docked with fenchone, co-crystallized ligands, and the standard drugs. The various proteins considered for the study were PDE2A (3ITU), PDE1B (4NPW), PDE4B (5LAQ), and a voltage-gated $\mathrm{Ca}^{2+}$ channel (6JPA). The protein coordinates $(\mathrm{x}, \mathrm{y}, \mathrm{z})$ search space and grid box size are provided in Table S1. The docking results shown in terms of binding affinity are represented in Table 1 . The docking methodology was validated by redocking the co-crystallized ligands, and the RMSD value and superimposed images of the same are shown in Table S2. Fenchone, being a very small molecule in comparison to PPV and VRP, showed a differing binding affinity than the standards. Fenchone presented 
binding affinities at $-5.2,-5.1,-5.3$, and $-6.3 \mathrm{kcal} / \mathrm{mol}$ with the receptors $3 \mathrm{ITU}, 4 \mathrm{NPW}$, 5LAQ, and 6JPA, respectively, while the standard drugs exhibited binding affinities at -8.3 , $-8.2,-8.4$, and -7.8 with the same receptors, respectively. Various hydrogen bindings and Van der Waal interactions were observed in the docked structures of FNC and PPV/VRP within the active domain of receptors, as shown in Figure 6 and Figure S1. Further, to explore the voltage-activated potassium channels, the RCSB database was extensively studied, and two isoforms, 6EBM and 7VNP, were utilized. The blind docking results were interesting, as shown in Table 2. With the potassium channel Kv1.2-2.1, FNC and retigabine (RTG) showed binding affinities at -5.7 and $-7.6 \mathrm{kcal} / \mathrm{mol}$, respectively, while with KCQN $4,-4.7$ and $-7.3 \mathrm{kcal} / \mathrm{mol}$, respectively.

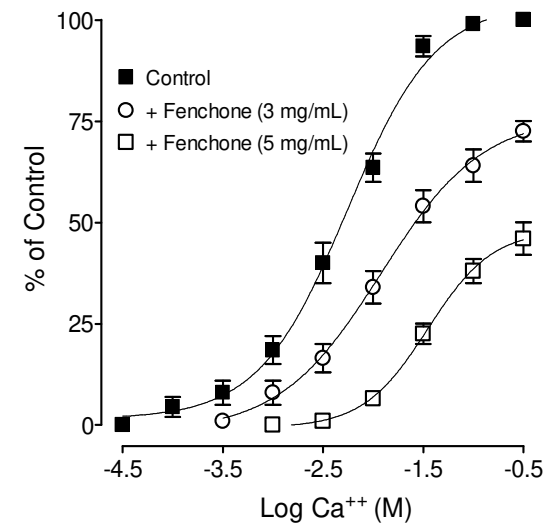

(A)

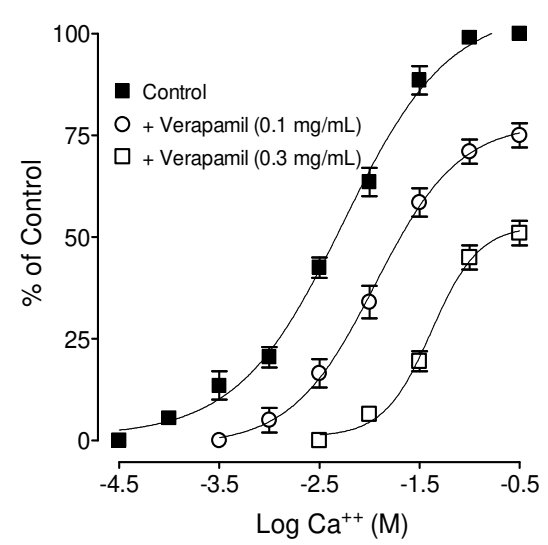

(B)

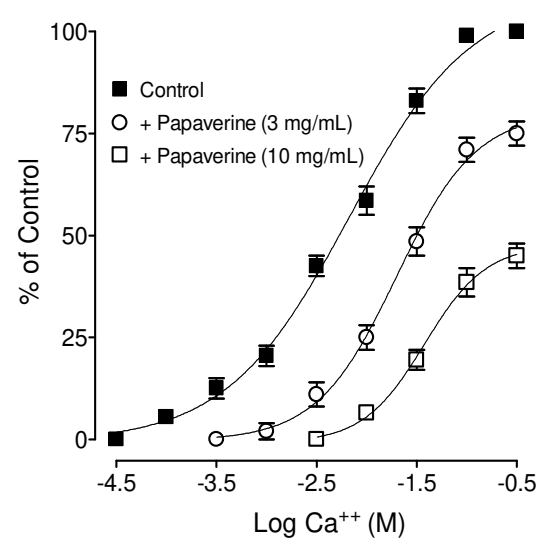

(C)

Figure 5. Concentration-response curves of $\mathrm{Ca}++$ in the absence and presence of the increasing concentrations of the $(\mathbf{A})$ fenchone, $(\mathbf{B})$ verapamil, and $(\mathbf{C})$ papaverine in isolated guinea pig tracheal preparations. Symbols represent mean $\pm \mathrm{SEM} ; n=4-5$.

Table 1. Molecular binding scores of fenchone and PPV/VPML with PDE isoforms and calcium channel (6JPA).

\begin{tabular}{|c|c|c|c|c|c|}
\hline \multicolumn{4}{|c|}{ Binding Scores } & \multicolumn{2}{|c|}{ Interacting Residues } \\
\hline $\begin{array}{l}\text { Receptors/ } \\
\text { Ligands }\end{array}$ & Fenchone & Co-Crystallized & Standard & Fenchone & Standard (PPV) \\
\hline 3ITU & -5.2 & -6.8 & $\begin{array}{c}-8.3 \\
(\mathrm{PPV})\end{array}$ & $\begin{array}{l}\text { His656, Tyr655, Ile826, } \\
\text { Phe830, Leu770 }\end{array}$ & $\begin{array}{l}\text { Tyr655, His656, His700, } \\
\text { Asp808, Leu809, Ile826, } \\
\text { Glu829, Phe830, Phe862 }\end{array}$ \\
\hline $4 \mathrm{NPW}$ & -5.1 & -8.5 & $\begin{array}{c}-8.2 \\
(\mathrm{PPV})\end{array}$ & $\begin{array}{l}\text { His223, His267, } \\
\text { Leu292, Met336 }\end{array}$ & $\begin{array}{l}\text { His223, His267, Gly269, } \\
\text { Asp370, Gln395, Leu388 }\end{array}$ \\
\hline 5LAQ & -5.3 & -8.3 & $\begin{array}{c}-8.4 \\
(\mathrm{PPV})\end{array}$ & $\begin{array}{l}\text { His450, Asn455, Leu475, } \\
\text { Asp447, Asp564, } \\
\text { Thr517, Glu476 }\end{array}$ & $\begin{array}{l}\text { Asn567, Leu565, Tyr405, } \\
\text { Ser454, His450, } \\
\text { His406, Gln615 }\end{array}$ \\
\hline 6JPA & -6.3 & -7.6 & $\begin{array}{c}-7.8 \\
(\mathrm{VPML})\end{array}$ & $\begin{array}{l}\text { Asn1303, Asn1301, Arg1302, } \\
\text { Lys241, Ser243, Tyr299, } \\
\text { Trp300, Asp303, }\end{array}$ & $\begin{array}{l}\text { Glu 342, Asp1385, Ser334, } \\
\text { Met1381, Phe1068, Gln1071, } \\
\text { Gly1072, Glu1073. }\end{array}$ \\
\hline
\end{tabular}




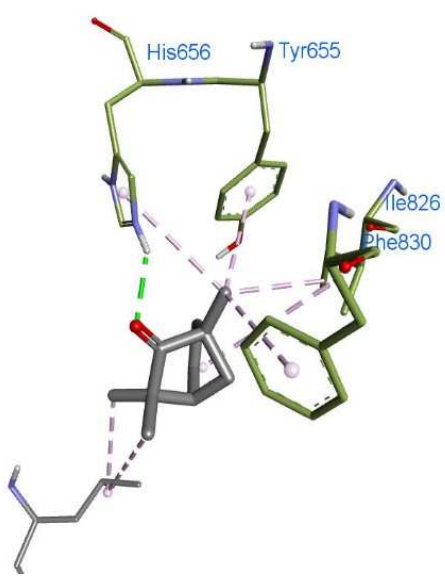

(A)

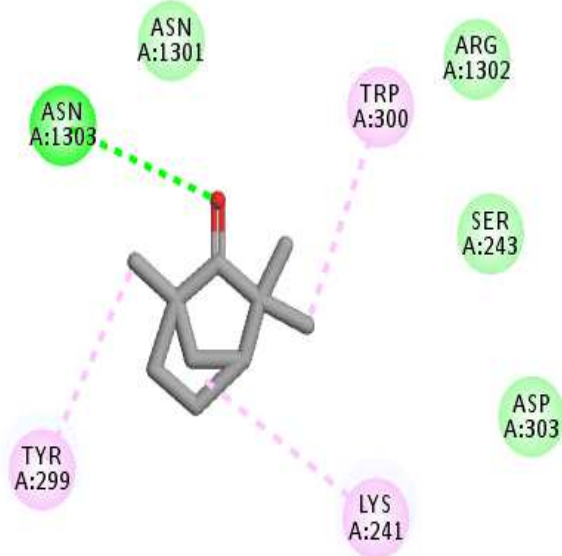

(C)

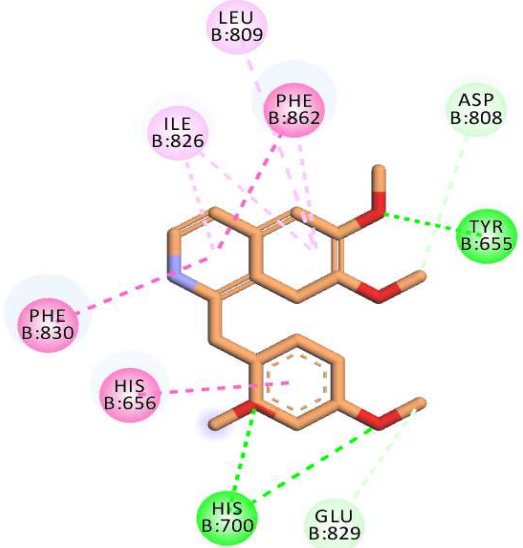

(B)

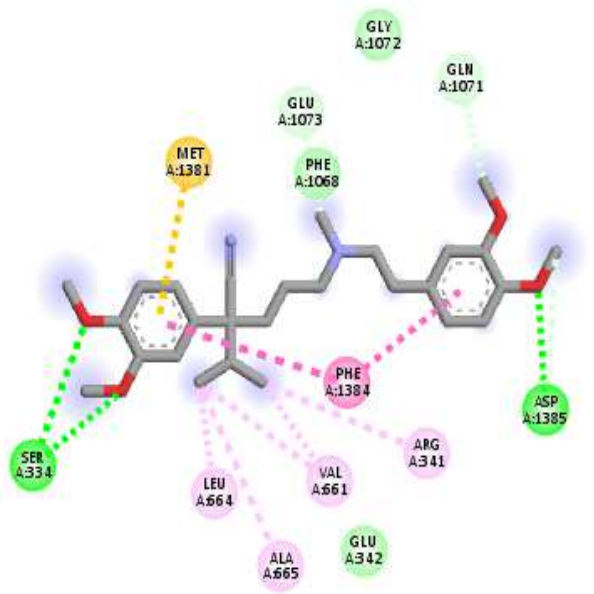

(D)

Figure 6. $6 \mathrm{~A}$ to $6 \mathrm{D}$ shows the ligand-receptor interactions. (A,B) show binding of PDE 4A(3ITU) with FNC and PPV, respectively. (C,D) show the binding modes of $\mathrm{Ca}++$ ion channel (6JPA) bounded with FNC and VRP. Dark green circles and lines show hydrogen bonds, while the light green spheres show Van der Waal interaction between ligands and residues.

Table 2. Molecular binding scores of fenchone and retigabine with voltage-gated potassium channel isoforms 7VPN (Human KCQN4) and 6EBM (Kv1.2-2.1).

\begin{tabular}{|c|c|c|c|c|}
\hline \multicolumn{3}{|c|}{ Binding Scores } & \multicolumn{2}{|c|}{ Interacting Residues } \\
\hline $\begin{array}{l}\text { Receptors/ } \\
\text { Ligands }\end{array}$ & Fenchone & Retigabine & Fenchone & Standard (RTG) \\
\hline 7VNP & -4.6 & -7.3 & $\begin{array}{l}\text { Gly E-319, Gly E-316, Gly G-316, Ser } \\
\text { E-320, Ser G-320, Ser C-320, Gly C-316, } \\
\text { Ser A-320, Gly A-319, Gly A-316, }\end{array}$ & $\begin{array}{l}\text { Pro D-358, LeuD-331, Val D-335, Val } \\
\text { D-365, Ile-F381, Lys F-384, Ile F-385, }\end{array}$ \\
\hline $6 \mathrm{EBM}$ & -5.7 & -7.6 & $\begin{array}{l}\text { Ser B-388, Leu B-389, Ile B-392, Ile } \\
\text { H-328, Leu H-331, Phe H-332, Val } \\
\text { H-335, Val H-365, }\end{array}$ & $\begin{array}{l}\text { Trp G-242, Gly G-245, Phe G-246, } \\
\text { Leu A-305, Phe G-311, Pro G-314, }\end{array}$ \\
\hline
\end{tabular}

\subsection{ADMET Profiling}

For any molecule to be a successful drug, it must have an acceptable ADMET profile. Table 3 represent the physicochemical parameters of the fenchone molecule, and when fenchone was subjected to ADMET prediction by the pkCSM server, it yielded acceptable ADMET values, as shown in Table 4. Drug likeness modules of fenchone exhibited an ac- 
ceptable ADMET profile to be considered a drug and have passed drug-likeness tests as per Pfizer, Veber, and Igan. The drug expressed $98 \%$ intestinal absorption and $63 \%$ blood-brain barrier permeability, without AMES and hepatotoxicity, only preseting skin sensitization.

Table 3. Physicochemical properties of fenchone.

\begin{tabular}{lc}
\hline & Physicochemical Properties \\
\hline Formula & $\mathrm{C} 10 \mathrm{H} 16 \mathrm{O}$ \\
Molecular weight & $152.23 \mathrm{~g} / \mathrm{mol}$ \\
Number of heavy atoms & 11 \\
Number of aromatic heavy atoms & 0 \\
Fraction Csp3 & 0.90 \\
Number of rotatable bonds & 0 \\
Number of H-bond acceptors & 1 \\
Number of H-bond donors & 0 \\
Molar Refractivity & 45.64 \\
TPSA & $17.07 \AA^{2}$ \\
Drug-Likeness & Pass by Pfizer/Veber/Egan \\
\hline
\end{tabular}

Table 4. ADMET properties of fenchone calculated in silico by pkCSM server-based program.

\begin{tabular}{|c|c|c|c|}
\hline Property & Model Name & Predicted Value & Unit \\
\hline \multirow{7}{*}{ A } & Water solubility & -2.668 & Numeric (log mol/L) \\
\hline & Caco2 permeability & 1.029 & Numeric $\left(\log\right.$ Papp in $\left.10^{-6} \mathrm{~cm} / \mathrm{s}\right)$ \\
\hline & Intestinal absorption (human) & 98.703 & Numeric (\% Absorbed) \\
\hline & Skin Permeability & -2.116 & Numeric $(\log K p)$ \\
\hline & P-glycoprotein substrate & No & Categorical (Yes/No) \\
\hline & P-glycoprotein I inhibitor & No & Categorical (Yes/No) \\
\hline & P-glycoprotein II inhibitor & No & Categorical (Yes/No) \\
\hline \multirow{4}{*}{$\mathrm{D}$} & VDss (human) & 0.247 & Numeric (log L/kg) \\
\hline & Fraction unbound (human) & 0.421 & Numeric $(\mathrm{Fu})$ \\
\hline & BBB permeability & 0.636 & Numeric $(\log B B)$ \\
\hline & CNS permeability & -2.067 & Numeric (log PS) \\
\hline \multirow{7}{*}{ M } & CYP2D6 substrate & No & Categorical (Yes/No) \\
\hline & CYP3A4 substrate & No & Categorical (Yes/No) \\
\hline & CYP1A2 inhibitor & No & Categorical (Yes/No) \\
\hline & CYP2C19 inhibitor & No & Categorical (Yes/No) \\
\hline & CYP2C9 inhibitor & No & Categorical (Yes/No) \\
\hline & CYP2D6 inhibitor & No & Categorical (Yes/No) \\
\hline & CYP3A4 inhibitor & No & Categorical (Yes/No) \\
\hline \multirow{2}{*}{$\mathrm{E}$} & Total Clearance & 0.085 & Numeric $(\log \mathrm{ml} / \mathrm{min} / \mathrm{kg})$ \\
\hline & Renal OCT2 substrate & No & Categorical (Yes/No) \\
\hline \multirow{10}{*}{$\mathrm{T}$} & AMES toxicity & No & Categorical (Yes/No) \\
\hline & Max. tolerated dose (human) & 0.751 & Numeric (log mg/kg/day) \\
\hline & hERG I inhibitor & No & Categorical (Yes/No) \\
\hline & hERG II inhibitor & No & Categorical (Yes/No) \\
\hline & Oral Rat Acute Toxicity (LD50) & 1.836 & Numeric $(\mathrm{mol} / \mathrm{kg})$ \\
\hline & Oral Rat Chronic Toxicity (LOAEL) & 1.982 & Numeric (log mg/kg/day) \\
\hline & Hepatotoxicity & No & Categorical (Yes/No) \\
\hline & Skin Sensitization & Yes & Categorical (Yes/No) \\
\hline & T. Pyriformis toxicity & 0.292 & Numeric $(\log u g / L)$ \\
\hline & Minnow toxicity & 1.218 & Numeric (log mM) \\
\hline
\end{tabular}

$\mathrm{A}=$ absorption, $\mathrm{D}=$ distribution, $\mathrm{M}=$ metabolism, $\mathrm{E}=$ excretion, and $\mathrm{T}=$ toxicity.

\section{Discussion}

Fenchone is found in a variety of aromatic plants, including F. vulgare and P. boldus, and is used to treat respiratory problems [9]. We, therefore, attempted to explore the possible 
bronchodilator effect of fenchone with its detailed pharmacodynamics using guinea pig tracheal muscles as an ex vivo model [26]. Its binding to different molecular targets was confirmed by in silico docking studies. In previous research, we discovered that spasmolytic effects of natural compounds are usually mediated via $\mathrm{K}^{+}$channel opening [35], PDE-inhibition [36], and/or $\mathrm{Ca}^{2+}$ channel blockade [37] hence the tracheal relaxant effects of fenchone were tested against sustained contractions induced by low $\mathrm{K}^{+}(25 \mathrm{mM})$, high $\mathrm{K}^{+}(80 \mathrm{mM})$, and CCh $(1 \mu \mathrm{M})$-mediated spasms [38]. Interestingly, fenchone selectively inhibited low $\mathrm{K}^{+}$-mediated contractions at lower concentrations compared to its spasmolytic effect against high $\mathrm{K}^{+}$, thus showing predominantly $\mathrm{K}^{+}$channels openers-like effect followed by $\mathrm{Ca}^{2+}$ channel blockade [36]. On the other hand, verapamil, a standard $\mathrm{Ca}^{2+}$ antagonist [39], inhibited both low and high $\mathrm{K}^{+}$-mediated contractions at comparable potencies as expected [40]. From a mechanistic standpoint, these trials effectively distinguish potassium channel openers from calcium channel blockers [27]. Based on the selectively high potency against low $\mathrm{K}^{+}$, fenchone was explored further to understand its action on the subtype of the $\mathrm{K}^{+}$channel involved in its spasmolytic effect. Fenchone spasmolytic effect was repeated in the tissues pretreated with different blockers, namely glibenclamide, an ATP-mediated $\mathrm{K}^{+}$channels blocker [21], 4-AP (voltage-dependent $\mathrm{K}^{+}$channel blocker) [20], and TEA; a nonselective $\mathrm{K}^{+}$channel blocker [19]. All the tested $\mathrm{K}^{+}$channel blockers shifted the inhibitory CRCs of fenchone towards higher concentrations, thus showing involvement of subtypes ATP-dependent, voltage-dependent, and non-specific $\mathrm{K}^{+}$channels activation. Different types of $\mathrm{K}^{+}$channels are abundant in the smooth muscle of the airways, modulating its physiological and pathophysiological states [41,42]. NO causes soluble guanylyl cyclase to be activated, resulting in the formation of cyclic guanosine monophosphate, which activates potassium channels via its dependent protein kinase [43]. $\mathrm{K}^{+}$channel activation causes cell membrane hyperpolarization, $\mathrm{Ca}^{2+}$ influx reduction, and inhibition of cellular excitability, resulting in smooth muscle relaxation [44,45]. These findings support an earlier study that found fenchone's antidiarrheal and antispasmodic effects are evoked by ATP-dependent $\mathrm{K}^{+}$channels [11].

Fenchone inhibited $\mathrm{CCh}$ and high $\mathrm{K}^{+}$-mediated spasm in tracheal chains at comparable concentrations similar to papaverine, a dual inhibitor of PDE and $\mathrm{Ca}^{2+}$ channels [46]. The papaverine-like PDE-inhibitory effect of fenchone was confirmed when it deflected inhibitory CRCs of isoproterenol constructed against CCh towards the left, thus showing potentiation. PDE inhibitors elevate the intracellular level of cyclic adenosine monophosphate (cAMP) by inhibiting PDE, which is a relaxant in smooth muscles and a stimulant in the heart [47]. The phosphodiesterase is a superfamily of enzymes and/are classified into 11 families in mammals, known as PDE1 to PDE11 [48]. The PDE enzyme type-4 (PDE-4) is considered more specifically involved in the smooth muscles of the airways; therefore, the inhibition of PDE4 will increase cAMP levels in tracheal tissues, which will result in bronchodilation [49]. Therefore we recommend further studies to precisely determine the inhibitory role of fenchone on PDE subtype-4. Verapamil, a standard $\mathrm{Ca}^{2+}$ channel blocker, showed significantly higher potency against high $\mathrm{K}^{+}$compared to $\mathrm{CCh}$ and did not affect isoprenaline inhibitory curves as was expected [50]. As fenchone inhibited complete efficacy against high $\mathrm{K}^{+}$at higher concentrations, further experiments were conducted to confirm its $\mathrm{Ca}^{2+}$ channel inhibitory activity. In $\mathrm{Ca}^{2+}$ free medium, pretreatment of tracheal tissues with fenchone shifted $\mathrm{CaCl} 2$ curves towards the right with suppression of maximum response, similar to verapamil and papaverine, thus suggesting a $\mathrm{Ca}^{2+}$ channel blocking effect [51]. The main limitation seen with PDE inhibitors or anticholinergics in the cardiovascular system is their cardiac stimulatory effect if applied alone [52,53]. However, the additional mechanism of $\mathrm{K}^{+}$channel opening and/or Ca++ channel inhibitory will perhaps offset the cardiac stimulation as both are cardio-suppressive [54]. As a result, the present study validates a novel combination of activities with synergistic and/or side-effect neutralizing potential [55].

Further docking studies of fenchone with PDE receptors and calcium channel receptors suggested the insight that Fenchone binds the same active binding site where the PPV 
and VPML were binding, respectively. Fenchone has exhibited PDE inhibitory activity similar to PPV but showed lesser binding affinity, and the small shape and size of the fenchone molecule can be regarded as the reason for this unique behavior. Fenchone and PPV showed binding with some common residues of PDE receptors such as Tyr655, His656, Ile826, and Phe823, in 3ITU; His223 and His267 in 4NPW, His450, Asn455, and Asp564, in 5LAQ. However, Fenchone showed interaction with some other residues as well which were not bonded to PPV and this might be the reason for the comparable activity of fenchone despite showing lesser binding affinity in silico. Likewise, fenchone exhibited a $\mathrm{Ca}^{2+}$ channel blocking effect comparable to VPML while binding to a separate set of residues in 6JPA. Further, the docking insights obtained from the voltage-activated potassium channels exhibited similar patterns, and the binding of fenchone was found to be in totally different pockets. In 6EBM, the standard drug bonded with the residues (Pro D-358, LeuD-331, Val D-335, Val D-365, Ile-F381, Lys F-384, Ile F-385) involving the chain D and F only while the fenchone was found to bind with (Ser B-388, Leu B-389, Ile B-392, Ile H328, Leu H-331, Phe H-332, Val H-335, Val H-365, Ile H-392) residues of Chain B and H as shown in Figure 7A,B. Fenchone showed profound potassium channel activation; it is evident that this is because of the binding at a different active binding site. Furthermore, fenchone comprises 11 heavy atoms compared to 22 heavy atoms in retigabine, making the former less complex than the latter. Retigabine has HBD 3 and HBA 3, whereas fenchone only has HBD 0 and HBA 1, giving the former higher binding energy when engaging with protein binding pockets. This might also explain why fenchone, while being a tiny molecule, surprisingly displayed $\mathrm{K}^{+}$Channel activation capabilities in vitro. A compound must have appropriate hydrophilic and lipophilic nature in order to be developed into a successful drug, and fenchone demonstrated adequate drug-likeness when calculated by the pkCSM software.

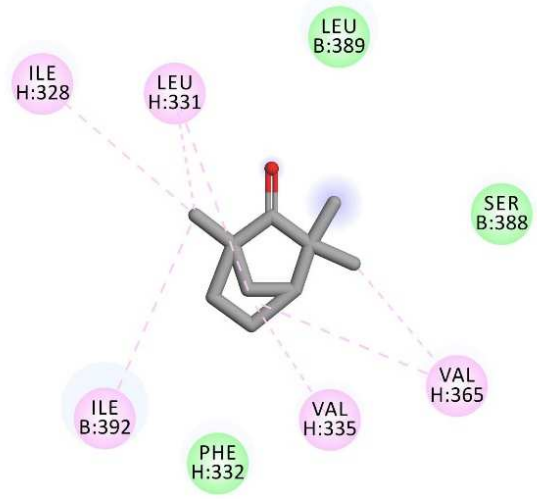

(A)

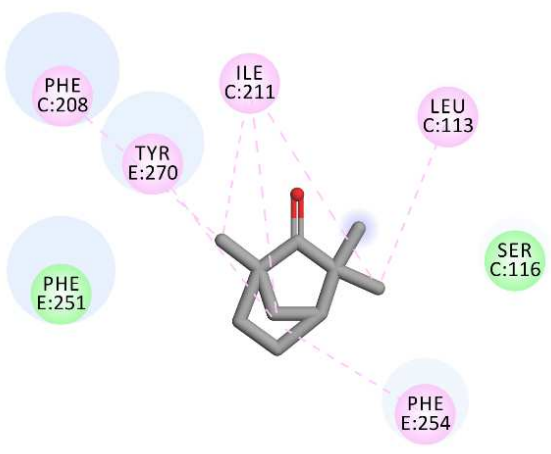

(C)

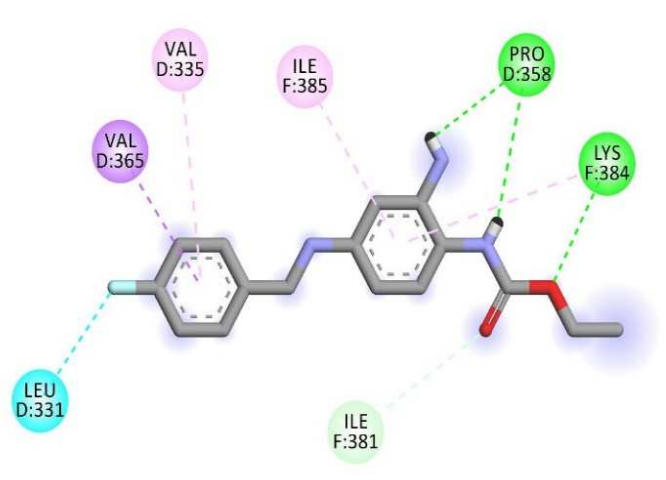

(B)

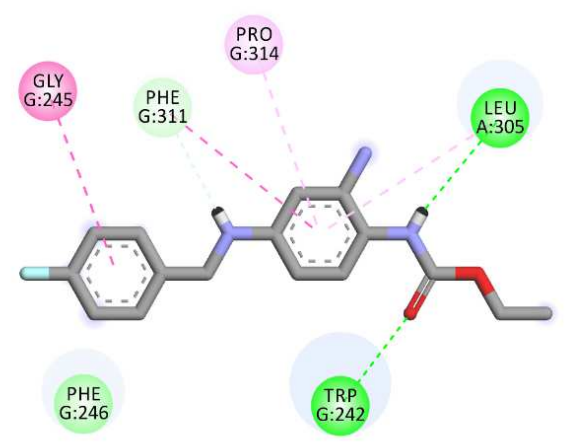

(D)

Figure 7. (A,B) Represent the $2 \mathrm{D}$ image of fenchone (FNC) and retigabine (RTG) docked within the voltage-gated potassium channel isoform 6EBM (Kv1.2-2.1). (C,D) Represent the 2D image of FNC and RTG interacting within the potassium channel isoform 7VPN (Human KCQN4). 


\section{Conclusions}

This study shows that fenchone possesses an antispasmodic effect in isolated guinea pig trachea mediated possibly by multiple pathways, predominantly by different types of $\mathrm{K}^{+}$channel activation followed by the dual inhibition of PDE and $\mathrm{Ca}^{2+}$ channels; additional mechanism(s) cannot be ruled out. Further in silico molecular docking studies provided insight for the binding of fenchone with the $\mathrm{Ca}^{2+}$ channel $(-5.3 \mathrm{kcal} / \mathrm{mol})$ and $\mathrm{K}^{+}$channel (-5.7), which also endorsed the idea of dual inhibition. This study may recommend further molecular assays to probe the precise pharmacodynamics involved and will therefore support the development of fenchone in the future for the treatment of hyperactive tracheal disorders.

Supplementary Materials: Figure S1: A to D show the ligand receptor interactions. Figure A-B and C-D show the binding mode of fenchone (FNC) and papaverine (PPV) with $4 \mathrm{NPW}$ and $5 \mathrm{LAQ}$, respectively. Dark green circles and lines show hydrogen bonds while the light green spheres are showing Vander Waal interaction between ligand and residues; Table S1: Vina Grid Search Space and box size of the receptors; Table S2: Redocked structures overlayed on the co-crystallized ligands.

Author Contributions: Conceptualization, N.U.R., M.N.A. and W.A.; methodology, N.U.R., A.S. and M.N.A.; software, N.U.R., A.S., W.A. and M.N.A.; formal analysis and investigation, N.U.R., A.S. and M.N.A.; resources, N.U.R., A.S., W.A. and M.N.A.; writing-original draft preparation, N.U.R., A.S. and M.N.A.; writing-review and editing, N.U.R., A.S., W.A. and M.N.A.; supervision, N.U.R. and M.N.A.; project administration, N.U.R. and M.N.A.; funding acquisition, N.U.R. and M.N.A. All authors have read and agreed to the published version of the manuscript.

Funding: The authors extend their appreciation to the Deputyship for Research \& Innovation, Ministry of Education in Saudi Arabia, for funding this research work through the project number (IF-PSAU-2021/03/18673).

Institutional Review Board Statement: The study was conducted according to the guidelines of the Declaration of Helsinki, and approved by the Bio-Ethical Research Committee (BERC) at Prince Sattam Bin Abdulaziz University (BERC-001-12-19).

Informed Consent Statement: Not applicable.

Data Availability Statement: Not applicable.

Conflicts of Interest: The authors declare no conflict of interest.

Sample Availability: Samples of the compounds are not available from the authors.

\section{References}

1. Barnes, P.J. New therapies for chronic obstructive pulmonary disease. Med. Princ. Pract. 2010, 19, 330-338. [CrossRef] [PubMed]

2. Cazzola, M.; Page, C.P.; Calzetta, L.; Matera, M.G. Pharmacology and therapeutics of bronchodilators. Pharmacol. Rev. 2012, 64, 450-504. [CrossRef] [PubMed]

3. Kasirajan, B.; Maruthamuthu, R.; Gopalakrishnan, V.; Arumugam, K.; Asirvatham, H.; Murali, V.; Mohandass, R.; Bhaskar, A. A database for medicinal plants used in treatment of asthma. Bioinformation 2007, 2, 105-106. [CrossRef] [PubMed]

4. Canning, B.J. Animal model of asthma and chronic obstructive pulmonary diseases. Pulm. Pharmacol. Therapeut. 2008, 21, 695. [CrossRef]

5. Gandevia, B. Historical review of the use of parasympatholytic agents in the treatment of respiratory disorders. Postgrad. Med. J. 1975, 51 (Suppl. 7), 13-20.

6. Barnes, P.J.; Hansel, T.T. Prospects for new drugs for chronic obstructive pulmonary disease. Lancet 2004, 364, 985-996. [CrossRef]

7. Wright, G.D. Unlocking the potential of natural products in drug discovery. Microb. Biotechnol. 2019, 12, 55-57. [CrossRef]

8. Shen, B. A New Golden Age of Natural Products Drug Discovery. Cell 2015, 163, 1297-1300.

9. Kim, T.; Song, B.; Cho, K.S.; Lee, I.S. Therapeutic Potential of Volatile Terpenes and Terpenoids from Forests for Inflammatory Diseases. Int. J. Mol. Sci. 2020, 21, 2187. [CrossRef]

10. Chi, T.; Ji, X.; Xia, M.; Rong, Y.; Qiu, F.Z.L. Effect of six extractions from Wuhu decoction on isolated tracheal smooth muscle in guinea pig. Zhong Guo Shi Yan Fang Ji Xue Za Zhi 2009, 15, 52-55.

11. Pessoa, M.L.S.; Silva, L.M.O.; Araruna, M.E.C.; Serafim, C.A.L.; Júnior, E.B.A.; Silva, A.O.; Pessoa, M.M.B.; Neto, H.D.; Lima, E.O.; Batista, L.M. Antifungal activity and antidiarrheal activity via antimotility mechanisms of (-)-fenchone in experimental models. World J. Gastroenterol. 2020, 26, 6795-6809. [CrossRef] [PubMed] 
12. Küpeli Akkol, E.; İlhan, M.; Ayşe Demirel, M.; Keleş, H.; Tümen, I.; Süntar, İ. Thuja occidentalis L. and its active compound, $\alpha$-thujone: Promising effects in the treatment of polycystic ovary syndrome without inducing osteoporosis. J. Ethnopharmacol. 2015, 168, 25-30. [CrossRef] [PubMed]

13. Algieri, F.; Rodriguez-Nogales, A.; Vezza, T.; Garrido-Mesa, J.; Garrido-Mesa, N.; Utrilla, M.P.; González-Tejero, M.R.; CasaresPorcel, M.; Molero-Mesa, J.; del Mar Contreras, M.; et al. Anti-inflammatory activity of hydroalcoholic extracts of Lavandula dentata L. and Lavandula stoechas L. J. Ethnopharmacol. 2016, 190, 142-158. [CrossRef] [PubMed]

14. NRC (National Research Council). Guide for the Care and Use of Laboratory Animals; National Academy Press: Washington, WA, USA, 1996; pp. 1-7.

15. Venkatasamy, R.; Spina, D. Novel relaxant effects of RPL554 on guinea pig tracheal smooth muscle contractility. Br. J. Pharmacol. 2016, 173, 2335-2351. [CrossRef] [PubMed]

16. Holroyde, M. The influence of epithelium on the responsiveness of guinea-pig isolated trachea. Br. J. Pharmacol. 1986, 87, 501-507. [CrossRef]

17. Van-Rossum, J.M. Cumulative dose response curves. II. Technique for making of dose-response curves in isolated organs and the evaluation of drug parameters. Arch. Int. Pharmacodyn. Therap. 1963, 143, 299-330.

18. Farre, A.J.; Columbo, M.; Fort, M.; Gutierrez, B. Differential effects of various Ca++ antagonists. Gen. Pharmacol. 1991, 22, 177-181. [CrossRef]

19. Cook, N.S. The pharmacology of potassium channels and their therapeutic potential. Trend Pharmacol. Sci. 1988, 9, 21-28. [CrossRef]

20. Satake, N.; Shibata, M.; Shibata, S. The inhibitory effects of iberiotoxin and 4-aminopyridine on the relaxation induced by beta1and beta2-adrenoceptor activation in rat aortic rings. Br. J. Pharmacol. 1996, 119, 505-510. [CrossRef]

21. Frank, H.; Puschmann, A.; Schusdziarra, V.; Allescher, H.D. Functional evidence for a glibenclamide-sensitive K+ channel in rat ileal smooth muscle. Eur. J. Pharmacol. 1994, 271, 379-386. [CrossRef]

22. Gilani, A.H.; Khan, A.U.; Jabeen, Q.; Subhan, F.; Ghafar, G. Antispasmodic and blood pressure lowering effects of Valeriana wallichii are mediated through K+ channel activation. J. Ethnopharmacol. 2005, 100, 347-352. [CrossRef] [PubMed]

23. Bolton, T.B. Mechanism of action of transmitters and other substances on smooth muscles. Physiol. Rev. 1979, 59, 606-718. [CrossRef] [PubMed]

24. Karaki, H.; Ozaki, H.; Hori, M.; Mitsui-Saito, M.; Amano, K.I.; Harada, K.I.; Miyamoto, S.; Nakazawa, H.; Won, K.J.; Sato, K. Calcium movements, distribution, and functions in smooth muscle. Pharmacol. Rev. 1997, 49, 157-230. [PubMed]

25. Godfraind, T.; Miller, R.; Wibo, M. Calcium antagonism and calcium entry blockade. Pharmacol. Rev. 1986, 38, 321-416.

26. Rehman, N.U.; Ansari, M.N.; Hailea, T.; Karim, A.; Abujheisha, K.Y.; Ahamad, S.R.; Imam, F. Possible tracheal relaxant and antimicrobial effects of the essential oil of Ethiopian thyme specie (Thymus serrulatus Hoschst. Ex Benth.): A multiple mechanistic approach. Front. Pharmacol. 2021, 12, 615228. [CrossRef]

27. Hamilton, T.C.; Weir, S.W.; Weston, A.H. Comparison of the effects of BRL 34915 and verapamil on electrical and mechanical activity in rat portal vein. Br. J. Pharmacol. 1986, 88, 103-111. [CrossRef]

28. Blattner, R.; Classen, H.G.; Dehnert, H.; Doring, H.J. Experiments on Isolated Smooth Muscle Preparations; Hugo Sachs Elektronik KG: March, Germany, 1978; pp. 53-71.

29. Lorenz, K.L.; Wells, J.N. Potentiation of the effects of sodium nitroprusside and isoproterenol by selective phosphodiesterase inhibitors. Mol. Pharmacol. 1983, 23, 424-430.

30. Lis-Balchin, M.; Patel, J.; Hart, S. Studies on the mode of action of essential oils of scented-leaf Pelargonium (Geraniaceae) Phytother. Res. 1998, 12, 215-217. [CrossRef]

31. Trott, O.; Olson, A.J. AutoDock Vina: Improving the speed and accuracy of docking with a new scoring function, efficient optimization, and multithreading. J. Comput. Chem. 2010, 31, 455-461. [CrossRef]

32. Biovia, D.S. Discovery Studio Modeling Environment; Release 2017; Dassault Systèmes: San Diego, CA, USA, 2016.

33. Rehman, N.U.; Ansari, M.N.; Samad, A. In Silico, Ex Vivo and In Vivo Studies of Roflumilast as a Potential Antidiarrheal and Antispasmodic agent: Inhibition of the PDE-4 Enzyme and Voltage-gated Ca++ ion Channels. Molecules 2020, 25, 1008. [CrossRef]

34. Pires, D.E.; Blundell, T.L.; Ascher, D.B. pkCSM: Predicting Small-Molecule Pharmacokinetic and Toxicity Properties Using Graph-Based Signatures. J. Med. Chem. 2015, 58, 4066-4072. [CrossRef] [PubMed]

35. Gilani, A.H.; Khan, A.U.; Ghayur, M.N.; Ali, S.F.; Herzig, J.W. Antispasmodic effects of Rooibos tea (Aspalathus linearis) is mediated predominantly through K+-channel activation. Basic Clin. Pharmacol. Toxicol. 2006, 99, 365-373. [CrossRef] [PubMed]

36. Rehman, N.U.; Khan, A.U.; Alkharfy, K.M.; Gilani, A.H. Pharmacological Basis for the Medicinal Use of Lepidium sativum in Airways Disorders. Evidence-based complementary and alternative medicine. eCAM 2012, 2012, 596524. [PubMed]

37. Bashir, S.; Memon, R.; Gilani, A.H. Antispasmodic and antidiarrheal activities of Valeriana hardwickii rhizome are putatively mediated through calcium channel blockade. Evid. Based Complement. Alternat. Med. 2011, 2011, 304960. [CrossRef]

38. Shah, A.J.; Zaidi, M.A.; Hamidullah, S.H.; Gilani, A.H. Antidiarrheal and antispasmodic activities of Vincetoxicum stocksii are mediated through calcium channel blockade. Bangl. J. Pharmacol. 2011, 6, 46-50. [CrossRef]

39. Fleckenstein, A. Specific pharmacology of $\mathrm{Ca}++$ in myocardium, cardiac pacemakers and vascular smooth muscle. Rev. Pharmacol. Toxicol. 1977, 17, 149-166. [CrossRef]

40. Robertson, D.W.; Steinberg, M.I. Potassium channel modulators: Scientific applications and therapeutic promise. J. Med. Chem. 1990, 33, 1529-1541. [CrossRef] 
41. Cunha, J.; Campestrini, F.; Calixto, J.; Scremin, A.; Paulino, N. The mechanism of gentisic acid-induced relaxation of the guinea pig isolated trachea: The role of potassium channels and vasoactive intestinal peptide receptors. Braz. J. Med. Biol. Res. 2001, 34, 381-388. [CrossRef]

42. Radulovic, M.; Anand, P.; Korsten, M.A.; Gong, B. Targeting Ion Channels: An Important Therapeutic Implication in Gastrointestinal Dysmotility in Patients with Spinal Cord Injury. J. Neurogastroenterol. Motil. 2015, 21, 494-502. [CrossRef]

43. Groneberg, D.; Voussen, B.; Friebe, A. Integrative Control of Gastrointestinal Motility by Nitric Oxide. Curr. Med. Chem. 2016, 23, 2715-2735. [CrossRef]

44. Quest, U. Potassium channel openers: Pharmacological and clinical aspects. Fund. Clin. Pharmacol. 1992, 6, 279-293. [CrossRef]

45. Lenz, T.; Wagner, G. Potential role of potassium channel openers for the treatment of cardiovascular disease. In Hypertension: Pathophysiology, Diagnosis and Management; Laragh, J.H., Brenner, B.M., Eds.; Raven Press: New York, NY, USA, 1995; pp. 2953-2968.

46. Rang, H.P.; Dale, M.M.; Ritter, J.M. Pharmacology, 4th ed.; Churchill Livingstone: New York, NY, USA, 1999 ; pp. $289-290$.

47. Smith, B.V.; Spina, D.; Page, C.P. Phosphodiesterase inhibitors. Br. J. Pharmacol. 2006, 47, 252-257. [CrossRef] [PubMed]

48. Lugnier, C. Cyclic nucleotide phosphodiesterase (PDE) superfamily: A new target for the development of specific therapeutic agents. Pharmacol. Ther. 2006, 109, 366-398. [CrossRef] [PubMed]

49. Martin, C.A.E.; Naline, E.; Bakdach, H.; Advenier, C. $\beta 3$-adrenoceptor agonists, BRL 37344 and SR 58611A, do not induce relaxation of human, sheep and Guinea-pig airway smooth muscle in vitro. Eur. Respir. J. 1994, 7, 1610-1615. [CrossRef] [PubMed]

50. Hsu, Y.T.; Liao, G.; Bi, X.; Oka, T.; Tamura, S.; Baudry, M. The PDE10A inhibitor, papaverine, differentially activates ERK in male and female rat striatal slices. Neuropharmacology 2011, 61, 1275-1281. [CrossRef]

51. Van Den Brink, F.G. The model of functional interaction. I. Development and first check of a new model of functional synergism and antagonism. Eur. J. Pharmacol. 1973, 22, 270-278. [CrossRef]

52. Nawrath, H. Action potential, membrane currents and force of contraction in cat ventricular heart muscle treated with papaverine. J. Pharmacol. Exp. Ther. 1981, 218, 544-549.

53. Nicholas, J.G. Anticholinergic agents in asthma and COPD. Eur. J. Pharmacol. 2006, 533, 36-39.

54. Roden, D.M. Antiarrhythmic drugs. In The Pharmacological Basis of Therapeutics, 11th ed.; Brunton, L.L., Lazo, J.S., Parker, K.L., Eds.; McGraw-Hill: New York, NY, USA, 2006; pp. 899-932.

55. Gilani, A.H.; Rahman, A. Trends in Ethnopharmacology. J. Ethnopharmacol. 2005, 100, 43-49. [CrossRef] 